\title{
An Investigation of Medical Discharges from the British Army 1979-1986
}

\author{
Major T O Jefferson \\ MD (Pisa), MSc, MRCGP, DRCOG, DTM\&H, RAMC \\ RAMC Training Centre, Keogh Barracks, Ash Vale, Hants GU12 $5 R Q$
}

SUMMARY: Male medical discharges from the British Army were analyzed for the years 1979-1986. There was a sudden increase in 1983 which reached a peak in 1985 caused by a significant rise in rates of discharge as a consequence of lower limbs and muscular overuse conditions, injuries from road traffic accidents, sports and falls. Training injuries showed an increase which, although substantial, failed to reach statistical significance. The highest increase took place in lowero limb and muscular overuse conditions in the youngest and most junior members of the infantry, especially when $\overline{\bar{\rho}}$. undergoing basic training. This category appears to be at the highest risk of medical discharge. Other teeth arms had the highest incidence of medical discharges from road traffic accidents. The importance of medical discharges may be misunderstood through the underestimation of their incidence and the absence of a capital valuation of the skills and ${ }^{\text {s }}$ experience of personnel discharged. The discharge of an infantry corporal with 8 years service may mean the loss of a $\vec{\circ}$ capital of at least $£ 149,599$. Any interventions aimed at reducing the number of discharges should be evaluated using the cost-benefit approach. Ways of reducing wastage are discussed.

\section{Introduction}

Each year the Ministry of Defence publishes triservice health statistics. These include the main causes of medical discharges from all three services. The data are published broken down by service, cause and year of discharge ${ }^{1}$.

No further analysis or breakdown by age, rank and unit is carried out routinely.

The data on male medical discharges from the Army show a decrease for the years 1979-1981 continuing the downward trend of the late 1970 s, followed by 2 years of relatively stable rates and then a sharp increase in the years 1983-1986. There is an increase in medical discharges as a consequence both of injury and disease since 1983. This is summarised in Figure 1, where the two overall causes of medical discharges, diseases and injuries, are presented by year of discharge.

In a small professional army such as the British one there are clear entry and retention medical requirements. Physically fit personnel are needed to endure the trials of the battlefield and wastage of manpower resources is inefficient.

A study was designed with the aim of investigating the recent increase in medical discharges from the British Army and some of its implications.

The objectives of the study were:

a) to describe the overall patterns of medical discharges of male personnel from the British Army for the years 1979-1986 caused by factors other than hostile action.

b) To detect and describe any factors other than hostile action which may have influence on the increase in male medical discharges from the British Army since 1983.

c) To explore the costs involved in the medical discharge of Army personnel.

d) To make recommendations, where appropriate, in order to reduce medical discharges and increase efficiency.

\section{The Reporting System}

Soldiers can be discharged at any point in their careers after being assessed by a medical board.

The proceedings of the board, recorded on Medical Form (FMED) 23 are subsequently sent to the Medic 10 Statistics Branch of the Ministry of Defence (Med Stats MOD) where the data contained are coded according $\overrightarrow{0}$ ICD 9 and stored on the Tri-Service Medical Statistips System (TRIMEDS). This is the source of the information contained in the annual tri-service healfo $\mathbb{D}$ statistics.

Personnel may also be discharged from the Arnq through an administrative procedure for reasons whis may be linked to medical factors. In this case information is fed into the TRIMEDS Data Base. This administrative procedure is used as a swifter alternative to medical boarding using the considerable latitude of $\frac{\mathrm{Q}}{\mathrm{D}}$ powers of a commanding officer. The rules for this $\varrho$ procedure are laid out in Queen's Regulations. Anecdotally this alternative to medical discharges is said to be used extensively with recruits. Steps were taken in the early 1980 s to limit this practice, but it is probably still widely used.

\section{Methods}

For the reasons given below it was decided to limit the $\frac{\vec{D}}{\vec{D}}$ study to the period 1979-1986, to exclude female $\stackrel{\varrho}{\rightleftarrows}$ personnel and disabilities caused by hostile action. The eighth version of the International Classification of 3 . Diseases (ICD 8) was in use prior to 1979, when the current one, ICD 9 , was introduced, and the different $\frac{}{3}$ coding is a potential source of confusion. At the time of writing data relating to discharges effected after 1986 were not available.

Female personnel are too few in number to make comparison and analysis meaningful and their terms of $N$ service and retention standards are different. Injuries $N$ 
resulting from hostile action are partly unpreventable as they are caused by factors beyond our control.

The information contained in the TRIMEDS Data Base was used to describe the overall patterns of male medical discharges. Because of resource constraints only the causes of discharges showing an increase in frequency were included in the study and further analyzed - for each discharge category numbers by age at discharge, unit, rank and occupation were examined. Data relating to a soldier's occupation at discharge were subsequently discarded as the coding categories tended to group the various employments and duties in the Army into 2 or 3 coding categories such as "Regimental Duties" which are too generic to allow analysis. Rates per 100000 United Kingdom trained males were calculated by year for the overall categories and per 100000 personnel serving in the rank, age or unit for the further subdivision analysis. Rates per 100000 were chosen in order to avoid excessive use of decimals in discharge categories with small numerators and so aid clarity. The manpower figures were provided by the Army Manpower Statistics Branch. Medical discharges from the other two services were not examined because of resource constraints. A review of factors which may have an influence on the increase of medical discharges was carried out by examining contemporary military literature on Army policy, entry and retention standards, commitments and conditions of service and will be referred to in the discussion. The review was supplemented by a series of interviews with senior Army officers, medical consultants, accountants and civil servants working in the MOD.

\section{Statistical Methods}

Trends in discharge rates over the period 1981-1986 (the period covering the years with approximately stable rates followed by the years demonstrating an increase in numbers and rates of discharges) were examined by calculation of the Spearman and Kendall Rank Correlation Coefficients (Spearman RCC and Kendall RCC). Such coefficients are part of non parametric statistical analysis methods, which allow analysis of data which are not normally distributed, or of rates, and are more appropriate in this case than the better known parametric tests such as the t-test. The significance of these two coefficients is generally similar, there is no strong reason to prefer one or the other for data of this nature ${ }^{2}$ and they both allow calculation of the likelihood of an event occurring by chance (the $p$ value). Significance levels, $p$, where presented, refer to the Spearman coefficient and values of $p$ less than or equal to 0.05 are considered to indicate significant increasing trends in rates of discharge over the period 1981-1986.

The coefficients are only considered to be meaningful where rates are based on averages of 15 cases per annum or more. Association between year and unit, age or rank for each of the main categories of increasing discharges were examined using the chi-squared test (where most expected cell frequencies were equal to or more than 5); significance levels of less than or equal to 0.05 indicate significant associations. The Somer's D and Kendall's Tau B and C statistics were examined to investigate trends in ages and ranks at the time of discharge over the study period. Analysis of the data was conducted using the Statgraphics statistical analysis software package.

\section{Methods of Costing}

To attempt to quantify some of the resource wastage due to premature discharge from the Army the estimated costs involved in training and maintaining an infantry soldier in role were itemised and valued. Some figures were only derived from estimates as exact costs were not available. This is due to the extreme diversity of employments, pay bands, courses, postings and allowances which the Army offers. Career items were costed in the following manner: the costs of recruiting suitable individuals and of recruit training, provided by the Army Accountancy Branch, were based on costs incurred in the training of an infantry soldier of the Light Division. Cost of in-role training was estimated using a standard formula of $39 \%$ of his yearly pay and allowances. This formula is used in Central Manageco ment Accounting at the Ministry of Defence ${ }^{3}$ and represents an average of training costs worked out for ${ }^{+}$ all ranks and occupations in the Army. Costing figures? for annual pay and allowances were derived from the Ministry of Defence capitation booklets ${ }^{4}$.

Estimates for pay and allowances for the previous years were derived by decreasing the figure by $10 \%$, the estimated effect of pay rises and inflation. All pay figures represent the average of the three Infantry employmento and salary bands for other ranks and include employer's contributions to National Insurance (ERNIC) and Pension (NEB).

This method of evaluating the loss to the Army of skilled personnel is based on the Human Capital economic approach to benefit evaluation ${ }^{5}$. This recognises the capital value which people represent and the benefits in increased productivity and availability of labour for productive work to be gained by safeguarding such capital. Additionally it provides an estimate of benefits to be compared with the costs of any interventions aimed at safeguarding and investing in such capital.

To calculate the cost to the Army of maintaining in employment personnel already medically boarded and awaiting final discharge the mean time between medical board and medical discharge was calculated for all diseases of the lower limbs in soldiers from 1979. The mean time between medical board and actual discharge multiplied by the cost of employing a soldier until his discharge, gives some idea of the economic burden to the Army. Loss of output, loss of future earnings, administrative costs of discharge, medical treatment, pension and diminished quality of life costs were not calculated. With a hypothetical case this is not possible. 
Results

For reasons of space only a selection of results are presented in table and figure format. Mention is made in the text of all findings in the study.

Some figures have been constructed using rates of discharges per 100000 males and others frequencies of discharges, on the vertical axis. This is to aid clarity of presentation for each data set and to present the statistics in an appropriate manner especially where small numbers of cases are involved.

\section{Overall Patterns of Medical Discharges}

The data are presented in Table 1 and Figure 1 where it can be seen that from a high in 1979 , medical discharges from all causes reached a low point in 1983 before increasing to a high level in 1985 .

The two main subcategories of cause of discharge (diseases and injuries) show a similar pattern. Discharges caused by diseases have a much higher incidence than discharges as a consequence of injuries (the ratio was nearly 4 to 1 in 1986).

In Table 1 and Figures 2, 3 and 4 (for selected years) the causes of discharge coded as diseases of the lower limbs (other than rheumatoid arthritis and ankylosing spondylitis) and diseases of the musculo-skeletal system show an increase in incidence from 1983 with an apparent peak in 1985. This increase is significant both from diseases of the lower limbs $(p=0.06$ Spearman RCC, and $p=0.04$ Kendall RCC, 1981-1986) and for musculo-skeletal diseases $(\mathrm{p}<0.05)$. These two causes alone since 1983 account for the general increase in discharges due to diseases in an otherwise declining category.

As can be seen in Table 1 and Figures 2, 3 and 4, the main causes of discharges following injuries show a

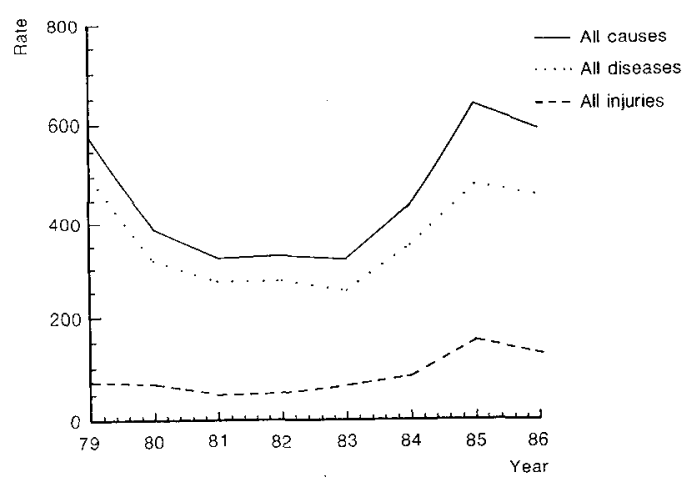

Fig 1. Discharge rates per 100,000 males from the British $\vec{\circ}$ Army 1979-1986.

decrease since 1979 followed by a significant increase which reached a peak in 1985 . They represent the majority of recent injury-related discharges. They are: injuries resulting from road traffic accidents, sports and fall and jump injuries, $(\mathrm{p}<0.05$ Spearman RCC, 19811986). Discharges from training and exercise injuries almost reached statistical significance $(\mathrm{p}=0$. Spearman RCC, 1981-1986).

Categories of discharge contributing to medic discharge rate increase since 1983.

The six categories contributing to the discharge ran increase (diseases of the lower limbs and of the musculo skeletal system, road traffic accident injuries, sports training and jump injuries) were further examined bo analysing their annual incidence in relation to the ags rank and present unit of the soldier concerned.

Annual discharges by cause and unit at discharge show that in all categories except injuries from road

Table 1. Medical discharge rates of males from the British Army 1979-1986. Discharges for all causes, for the two main categories and increasing causes by year of discharge. Rates are per 100000 serving males. Note: RTA = Road traffic accident MSS = Musculo-skeletal system

\begin{tabular}{|c|c|c|c|c|c|c|c|c|c|}
\hline & $\begin{array}{l}\text { All } \\
\text { causes }\end{array}$ & $\begin{array}{c}\text { All } \\
\text { diseases }\end{array}$ & $\begin{array}{c}\text { Diseases of } \\
\text { Lower Limbs }\end{array}$ & $\begin{array}{l}\text { Diseases of } \\
\text { the MSS }\end{array}$ & $\begin{array}{c}\text { All Injuries } \\
\text { (Excl Hostile } \\
\text { Action) }\end{array}$ & $\begin{array}{l}\text { Training } \\
\text { Injuries }\end{array}$ & $\begin{array}{c}\text { RTA } \\
\text { Injuries }\end{array}$ & $\begin{array}{l}\text { Sports } \\
\text { Injuries }\end{array}$ & $\begin{array}{c}\text { Fall } \\
\text { Injurie }\end{array}$ \\
\hline \multicolumn{10}{|l|}{ Year } \\
\hline 1979 & 577 & 502 & 75 & 80 & 69 & 12 & 16 & 7 & 2 \\
\hline 1980 & 388 & 318 & 59 & 34 & 68 & 9 & 27 & 7 & 11 \\
\hline 1981 & 320 & 274 & 53 & 24 & 49 & 14 & 18 & 3 & 2 \\
\hline 1982 & 330 & 276 & 54 & 43 & 49 & 14 & 22 & 2 & 3 \\
\hline 1983 & 321 & 254 & 45 & 27 & 50 & 10 & 18 & 6 & 4 \\
\hline 1984 & 439 & 352 & 88 & 55 & 80 & 19 & 26 & 11 & 10 \\
\hline 1985 & 637 & 483 & 148 & 97 & 150 & 36 & 33 & 35 & 26 \\
\hline 1986 & 589 & 461 & 165 & 101 & 120 & 36 & 31 & 22 & 21 \\
\hline
\end{tabular}




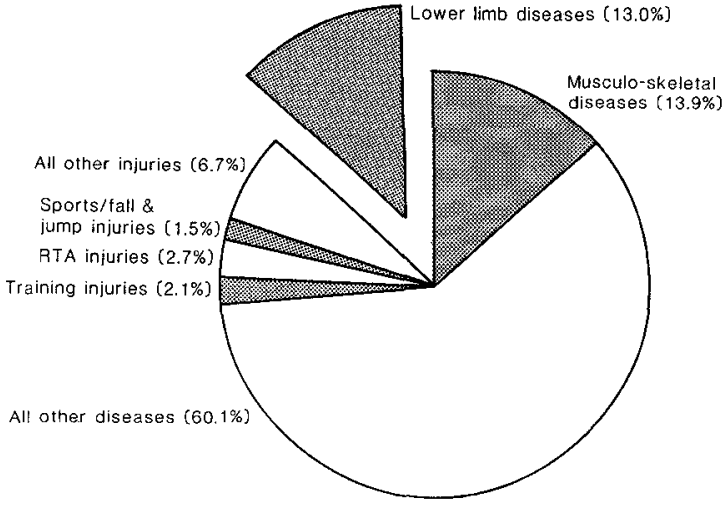

Fig 2. Medical discharges of males from the British Army 1979 (875 cases).

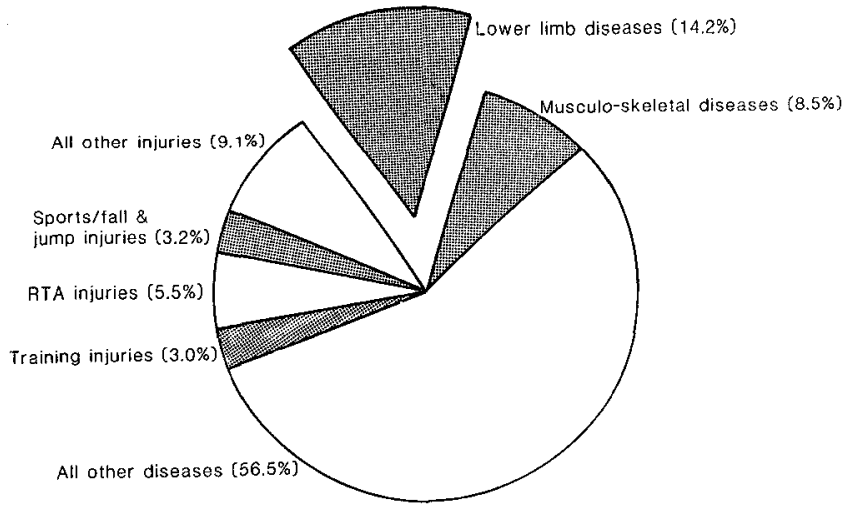

Fig 3. Medical discharges of males from the British Army 1983 (494 cases).

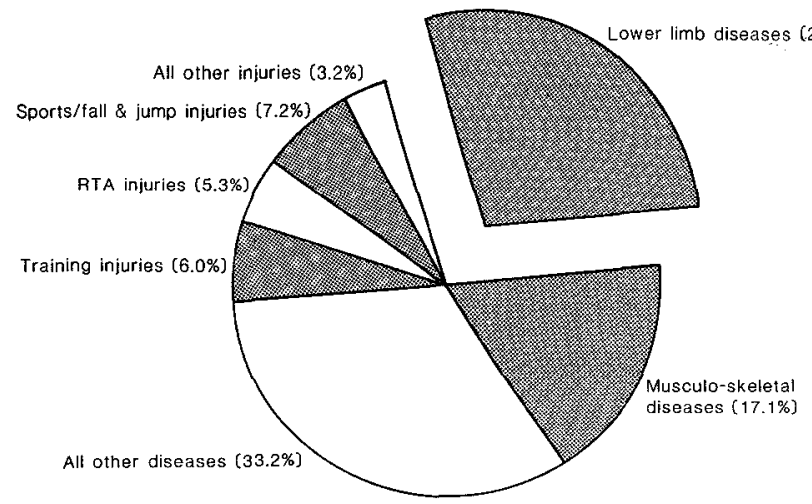

Fig 4. Medical discharges of males from the British Army 1986 (911 cases). traffic accidents infantry soldiers have higher discharge rates than other teeth arms (Cavalry, Royal Artillery, Royal Signals and Royal Engineers) and Corps (all other Units) for each year. Other teeth arms have the highest rates of discharges for injuries resulting from road traffic accidents in 1980 and 1986.

All the categories show a rapid increase since 1983 with a possible peak in 1985. The highest incidence of discharges is shown by infantry soldiers with diseases of the lower limbs (Fig. 5). Significantly increasing trends since 1981 are seen in infantry soldiers for discharges caused by diseases of the musculo-skeletal system (Fig. 6) and training and exercise injuries (the latter since 1983) and in other teeth arms for road traffic accident injuries $(p<0.05)$. The distribution of discharges across the units is significantly associated with the year of study for lower limb diseases and road traffic accident injuries ( $p<0.05$, chi-squared test).

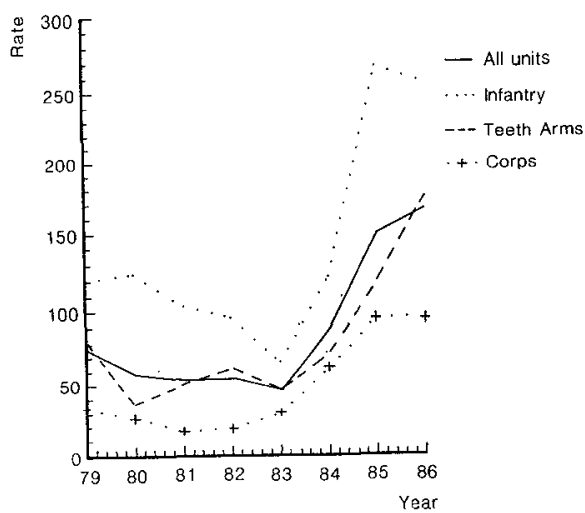

Fig 5. Diseases of the Lower Limbs. Discharge rates per 100,000 personnel.

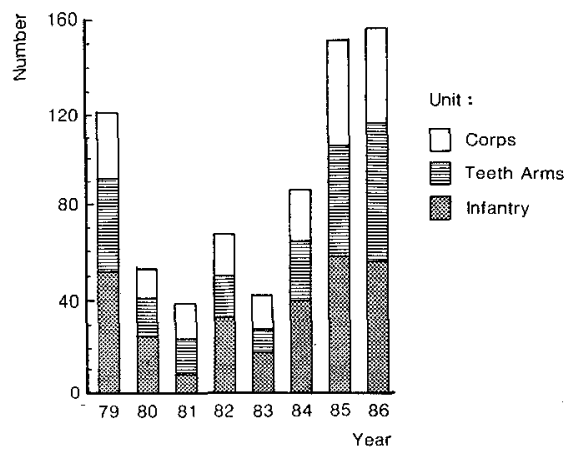

Fig 6. Diseases of the Musculo-Skeletal System. Number of Discharges by Employment. 
Yearly discharges by cause and age at discharge show that soldiers below the age of 20 have the highest discharge rates for five out of the six categories.

Since 1983 discharges from injuries as a result of road traffic accidents have a higher incidence in soldiers aged 20 to 29 inclusive. For the period 1981-1986 the time trends are increasing significantly for diseases of the

- lower limbs, musculo-skeletal system (see Figs. 7 and 8) and road traffic accident injuries in the 20 to 29 age group $(\mathrm{p}<0.05$, Spearman RCC). Lower limb diseases account for the highest discharge rates in soldiers below the age of 20 throughout the years. Age at discharge is significantly associated with year of study for diseases of the lower limbs and of the musculo-skeletal system $(p<$ 0.01 , chi-squared) and there is some indication of a tendency towards younger ages at discharge in the later years (Somer's D and Kendall's Tau statistics taking small negative values).

Yearly discharges by cause and rank at discharge show that apprentices and juniors (who are aged under 18) have the highest rates for lower limb diseases with an eightfold increase of the rate since 1983 (see Table 2), musculo-skeletal diseases, sports injuries and falls. Privates (which include adult recruits) have the highest rates for injuries from training (in 1986) and road traffic accidents.

Officers show overall very low incidence of discharges. Significant increasing trends in discharges attributable to diseases of the lower limbs are seen in apprentices/juniors and privates and in apprentices/ juniors for the musculo-skeletal system $(p<0.05)$. Rank at discharge is associated with year of study for diseases of the lower limbs $(p<0.01)$ and the musculo-skeletal system $) p=0.06)$. There is some indication of a tendency towards more junior ranks in the later years (Somer's D and Kendall's Tau statistics).

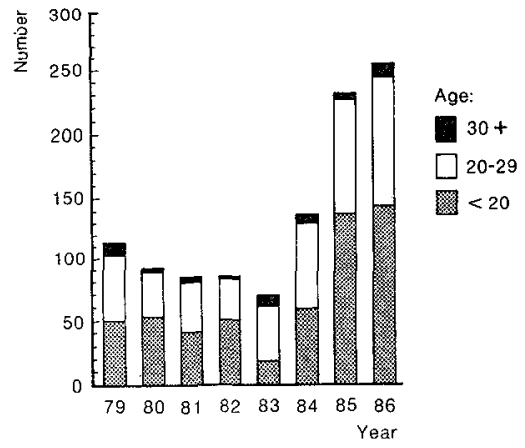

Fig 7. Diseases of the Lower Limbs. Number of Discharges by Age.

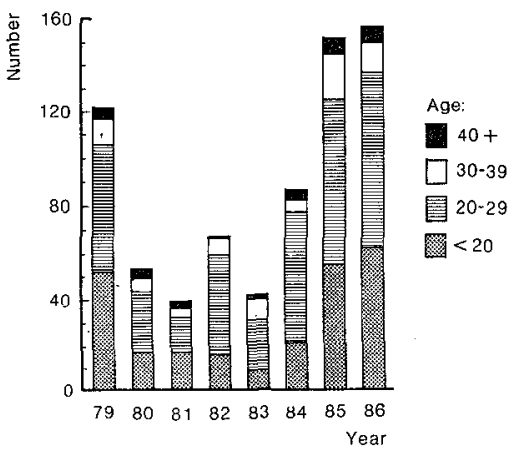

Fig 8. Diseases of the Musculo-Skeletal System. Number of Discharges by Age.

Table 2.

Discharge rates for diseases of the lower limbs by rank and year. Rates are per 100,000 male personnel.

\begin{tabular}{|c|c|c|c|c|c|}
\hline Rank & Apprentice/Junior & Private & WO \& NCOs & Total Soldiers & All Ranks \\
\hline \multicolumn{6}{|l|}{$\overline{\text { Year }}$} \\
\hline 1979 & 196 & 126 & 33 & 82 & 75 \\
\hline 1980 & 311 & 77 & 17 & 64 & 58 \\
\hline 1981 & 343 & 65 & 18 & 59 & 54 \\
\hline 1982 & 384 & 88 & 13 & 62 & 55 \\
\hline 1983 & 126 & 84 & 18 & 50 & 46 \\
\hline 1984 & 342 & 174 & 14 & 97 & 88 \\
\hline 1985 & 772 & 268 & 30 & 166 & 149 \\
\hline 1986 & 1077 & 287 & 31 & 185 & 167 \\
\hline Notes: & \multicolumn{5}{|c|}{$\begin{array}{l}\text { WOs and NCOs includes all ranks from Lance Corporal to Warrant Officer Class } 1 . \\
\text { Officers are included in All Ranks. }\end{array}$} \\
\hline
\end{tabular}




\section{Factors Affecting Discharges}

The only recent change in Army policy which may have affected discharges occurred in 1985 when the Common Military Syllabus for Recruits (CMSR) was introduced.

The special to arms training courses, which a recruit undertakes after the CMSR, were also shortened. For example, the new syllabus shortened the course of recruit basic instruction to 8 weeks. This implied the revision of the subjects taught and an increased pressure on time and content to maintain the same standards.

There have been no other recent changes in recruiting standards and retention policy. The only new Army commitment since the early 1980 s has been the garrisoning of the Falkland Islands. This is however a small commitment. Data for accidents by theatre of occurrence are not available.

The introduction of new combat high boots has recently been blamed for the increase in lower limb problems. The Army Personnel Research Establishment (APRE) study on recruits in training ${ }^{6}$ has shown that the new boot only causes problems if it is worn on runs without a period of initial wear. The application of this principle in turn was thought to reflect on the standard of supervision received by the recruits. In the APRE study, the better the supervision, for instance with the application of an injury limitation programme, the smaller the wastage of recruits.

The incidence of reported road traffic accidents involving Army vehicles has increased since 1983 when there were 7981 accidents compared with 10174 in 1987. 684 accidents involved casualties in 1983 compared with 790 in 1987 (source: Traffic Accident Analysis System, TAAS).

The age standardized mortality ratio (SMR) for road traffic accidents in the Army males is high at $\mathbf{1 7 5}$ for the years 1982-1986 compared with the UK male population (which has a SMR of 100 , this being the baseline).

\section{Resource Wastage}

Cost estimations are presented in Tables 3 and 4 and Figure 9. Table 3 and Figure 9 illustrate the average cost to the Army of training an infantry soldier to the rank of corporal for the years 1980 to 1988 .

The monetary reconstruction of the career of such a soldier, although simplified, is based on a real model. The choice of rank and trade for the example was made because of the importance to the Army of such men, considered the "cutting edge" of any army. Such a career was considered reasonably representative of an infantry junior NCO's. Any injury (such as a consequence of a road traffic accident) and discharge at the 8 year point would result in the loss to the Army of an estimated capital of nearly $£ 150000$. The table does not include the cost of the accident, the soldier's subsequent loss of earnings, a notional sum for distress caused by the accident, an adjustment for a reduced quality of life and the cost to the State of his disability pension, all items necessary for a complete economic appraisal. Table 4 gives the estimated daily cost ( $£ 107)$ of an adult infantry recruit in the financial year $1987 / 1988$. The mean time from medical board to actual discharge for diseases of the lower limbs has increased from three months in 1978 to four months in 1986. This represents a mean cost to the Army of $£ 14090$ per recruit awaiting final discharge after medical boarding for a disease of the lower limbs in 1986 (the figure was obtained by multiplying the dail $\bar{\Phi}$ cost of a recruit by 4 working months and adding the initial recruiting costs).

\section{Discussion}

Over the years several small studies have bee conducted looking into different aspects of medicia discharges from the British Army. The majority studies have looked at injuries and discharges during basic training, where historically the maximum incidence of injuries is found. In 1977 Wilson, Evans-

\begin{tabular}{|c|c|c|c|c|c|c|c|c|c|c|}
\hline \multirow{2}{*}{$\frac{\text { Rank }}{\text { Year }}$} & \multirow{2}{*}{$\begin{array}{r}\text { Recruit } \\
1980\end{array}$} & \multicolumn{5}{|c|}{ Private } & \multicolumn{2}{|c|}{ Lance Corporal } & \multirow{2}{*}{$\begin{array}{c}\text { Corporal } \\
1988\end{array}$} & \\
\hline & & 1981 & 1982 & 1983 & 1984 & 1985 & 1986 & 1987 & & \\
\hline $\begin{array}{l}\text { Pay \& } \\
\text { Allowances }\end{array}$ & $1060^{*}$ & 9343 & 10381 & 11927 & 12145 & 12752 & 12857 & 13145 & 19586 & \\
\hline Recruiting & 750 & & & & & & & & & \\
\hline Training & 5824 & 3643 & 4048 & 4651 & 4736 & 4973 & 5014 & 5126 & 7638 & \\
\hline Total & 7634 & 12986 & 14429 & 16578 & 16881 & 17725 & 17871 & 18271 & 27224 & $\begin{array}{c}\text { Grand } \\
\text { Total } \\
149599\end{array}$ \\
\hline
\end{tabular}

Note: ${ }^{*}$ This figure represents 3 months' recruit training.

Table 3.

Summary of estimated costs (in £ Sterling) for training and maintenance in role of an infantry corporal. All figures are gross of Tax and include ERNIC and NEB. 
Table 4. Estimated daily cost of an adult infantry recruit (1987-1988) in training. Pay \& allowances are gross of tax and include ERNIC and NEB.

\begin{tabular}{lll}
\hline & $\begin{array}{l}\text { Common Military } \\
\text { Syllabus }\end{array}$ & $\begin{array}{l}\text { Special to Arm } \\
\text { Training }\end{array}$ \\
\hline $\begin{array}{l}\text { Pay \& } \\
\text { Allowances }\end{array}$ & $\begin{array}{l}44 \text { days @ } \\
£ 19 \text { per day }\end{array}$ & $\begin{array}{l}90 \text { days @ } \\
£ 19 \text { per day }\end{array}$ \\
Recruiting & $£ 1250$ & \\
Training & 44 days@ & 90 days @ \\
Costs & $£ 88$ per day & $£ 88$ per day \\
\hline & Total & $\begin{array}{l}\text { Total } \\
£ 9630\end{array}$ \\
& $£ 5958$ & Grand Total \\
& & \\
& & \\
\hline
\end{tabular}

Smith and Oelman carried out a three year study of patello-femoral pain in a training establishment. They found that his accounted for approximately $4.5 \%$ of discharges for medical reasons.

They identified two different groups of patients. Those with acute traumatic onset who responded well to conservative treatment and those with an insidious onset during training and a pre-service history of knee pain. This last group accounted for the majority of discharges. They recommended better entry medical examinations ${ }^{7}$.

Their findings were at odds with those of Sinclair ${ }^{8}$, a GP in Scotland who carried out recruitment medicals for the Army. In a small study of 208 potential recruits screened on entry there was a $19 \%$ medical failure rate, but none of those who went on to basic training were subsequently medically discharged. He concluded that regulations covering medical fitness are adequate.

Sinclair's methodology is unclear; he does not state whether his survey includes administrative discharges or purely proceedings of medical boards. If the former, the lack of discharges in his study cohort is difficult to reconcile with discharge rates from other sources; on the other hand if the source of data on discharges is TRIMEDS, there is a possibility of underestimation of the number of discharges.

Lynch-Blosse ${ }^{9}$ studied medical discharges (including discharges under the administrative procedure) of an intake of recruits in 1984 and found a true medical wastage rate of $3.3 \%$, with general wastage rate in the intake of $24 \%$ during basic training. Routinely collected statistics put medical wastage at $0.06 \%$ of the intake. This discrepancy was due to many recruits being discharged through the administrative procedure and not appearing on routine data as medical discharges. This study appears to confirm that the use of the

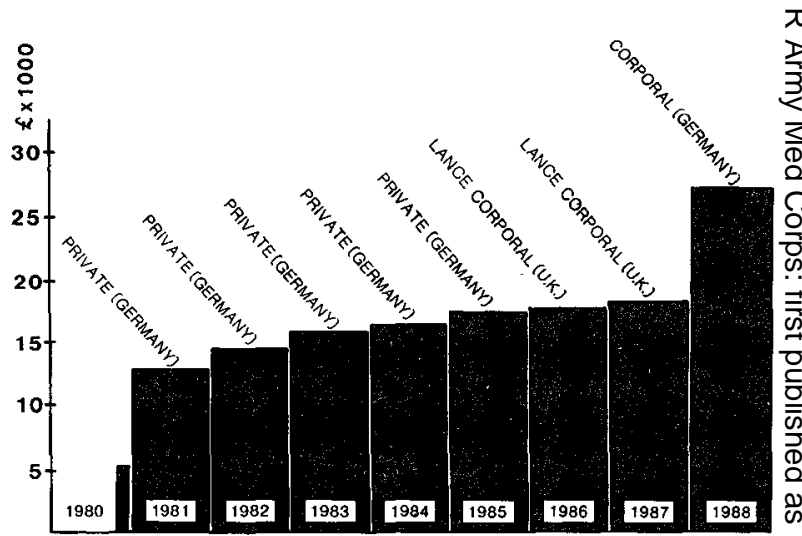

Fig 9. Reconstruction of cost of pay (inclusive of ERNIC and NEB, gross of tax) allowances and training of an $\vec{\omega}$ Infantry Corporal who joined the army in September $\stackrel{\sigma}{\omega}$ 1980 and who was discharged on 31 December 1988.

administrative procedure is a confounding factor whe examining medical discharge rates and leads to the underestimation of numbers of medical discharges and their effects on the Army. It did not however study time trend of medical discharges effected under the administrative procedure. This is likely to vary fro 0 year to year in response to service factors, thereb $\mathbb{\Phi}$ distorting the true discharge rates.

A small pilot study carried out in 1984 is in broagd agreement with Lynche-Blosse's figures (C gु Lewthwaite, personal communication).

The APRE study analysed lower limb injuries recruits in training. Its main findings were a high physical training and fitness level prior to enlistment of the majority of recruits, and the reduction in wastage obtained by a rigorous overuse injury control $\overrightarrow{0}$ programme at unit level. The implementation of a simple measure such as initial running in training shoes rather than stiff new boots considerably decreased the rate of injury ${ }^{6}$.

Tointon ${ }^{10}$ carried out a small survey of sports injuries in the three Services, and found that football and rugby injuries were the most common but had difficulty in explaining the diminishing trend of the late $70 \mathrm{~s}$ and the rise in the early 1980s. This study was however limited to the most serious injuries, (needing hospitalization for at least two nights and leading to a medical discharge) and did not take into account the much more common less serious injuries.

Literature provides few comparisons. A survey of 윽 accidental injuries in the US Navy ${ }^{11}$ found an inverse $\rightarrow$ relationship between age and rank and risk of injury. Further comparisons are difficult because of different recruiting and retention standards.

Five of the six categories of medical discharges $\stackrel{N}{N}$ 
showed significant increase since 1983. Training injuries showed a substantial increase since 1983 which failed to reach statistical significance. Numerically the greatest increases have taken place since 1983 in lower limb and muscular overuse conditions.

The highest incidence of these is in the youngest and most junior members of the infantry. The APRE ${ }^{6}$ study showed that there is no evidence that we are recruiting less fit personnel or that our boots are to be blamed. Retention standards have not changed. It is possible that the intensification of training since 1983 has had an adverse effect on the standard of supervision enjoyed by soldiers, especially while undergoing basic training, a fact that has been empirically recognized and has led to the lengthening of the CMSR to 10 weeks. The competition for skilled, experienced and careerworthy personnel in trade and employment groups required for training inevitably weighs against training establishments.

The increase in discharges for lower limb and muscular diseases is associated with the shortening of the period of basic training. No statement of cause and effect is possible, but a better evaluation of the consequences of such a policy should be carried out.

There is no apparent reason for the increased numbers of road traffic accidents although the quality of the data from TAAS must be questioned as it only includes data on military personnel involved in accidents while in MOD vehicles and not in private ones.

TAAS shows only $2 \%$ of Service road traffic accidents associated with excessive alcohol intake; this contrasts with the findings of other studies which showed that $64 \%$ of the 931 British Army male deaths associated with alcohol between 1966 and 1977 had taken place as a result of road traffic accidents ${ }^{12,13}$.

The need for reliable data on circumstances of road traffic accidents is paramount if a realistic accident prevention policy is to be devised. Additionally, a costing system could be introduced with yearly cost reports along the lines of the Department of Transport Highway Economics Notes ${ }^{14}$.

A model for a costing system for military road traffic accidents based on TAAS data was proposed in the early 1980 s but never adopted ${ }^{15}$.

Ways of improving the military road traffic accident reporting system are being studied with the proposed introduction of a new Information Management and Provision of Accident Costs and Trends (IMPACT) system. IMPACT will provide better quality and more timely data on both circumstances and costs of road traffic accidents and is destined to replace TAAS ${ }^{16}$. Better knowledge of the occurrence and implications of such accidents will aid cost-benefit appraisal of interventions to prevent accidents.

It appears that considerable time and money are wasted in the bureaucratic formalities of some medical discharges. The recent increase in the mean time between the assessment of an injured soldier and his medical discharge is costly. Ways of further elucidating the causes of the problem might entail a study of a random sample of discharges.

The occupational codes for TRIMEDS are too broad in coverage to provide specific information pertaining to the occupational circumstances of discharges. There is a need for a revision of the coding in the system in order to provide more useful occupational information.

A proper evaluation of the problem and waste $\stackrel{P}{\rightarrow}$ represented by medical discharges may not be possible if there is a chronic underestimation of the numbers of soldiers discharged and their capital value to the Army.

Extending Lynche-Blosse's figures to all discharges, the numerical underestimation may be as much as fiftyfold.

To the author's knowledge no previous calculation of a soldier's capital value had been made. This makes economic evaluation of interventions directed at reducing the risk of discharge (from injury, death, or any other cause) impossible. For example, the cost of the provision of training shoes for recruits and the time spent by instructors to supervise an injury reduction programme in recruits should be measured against the benefit of retaining in service the human capital several thousand pounds represented by a recruit if training. As each soldier represents a unique investment for the Army, financed by the taxpayer, and as the Arm is responsible for the health of its employees, a highe priority should be given to reducing the risk of premature discharge. The same principle should appl to all causes of discharges, not only medical ones.

We may need to invest more resources in order to safeguard our capital and diminish waste. This especially important given the envisaged shortage Army recruitable personnel in the next 20 years ${ }^{17}$.

\section{Recommendations}

On the basis of this study the following recommendations are made:

1. The introduction of better supervision of training in order to reduce wastage through medical discharges.

This is especially important in infantry personnel below the age of 20 and at or below the rank of Private. Ways of doing this might include:

The rigorous application of injury limitation programmes.

A better realization by the Army of the capital value of its main asset, people, by a wider circulation of medical discharge figures and their economic implications and of the results of important studies such as the APRE one to all personnel supervising training.

2. A review of the current administrative discharge reporting procedures. This would also provide the Medical Statistics Branch of the MOD with a better estimate of the numbers of soldiers being discharged for medical reasons, either as a principal or as a concurrent reason. 
3. The introduction of a system, based on the human capital concept, of measuring, evaluating and costing the monetary value to the Army of its personnel.

This need only be based on average costs calculated once only, but updatable with a fixed formula.

4. The introduction of a cost benefit approach to evaluate measures to reduce the risk of injury, disease or death.

5. A revision of the routine collection of data on road traffic circumstances, and the introduction of routine costing of accidents.

6. A monitoring of discharge procedures and a speeding up of the boarding to discharge time.

7. A review of the occupational coding procedure from the start of the documentation through to the output from the Medical Statistics Branch, MOD.

\section{Acknowledgements}

The author would like to thank the late Professor Patrick Hamilton and Dr Jenny Roberts of the London School of Hygiene and Tropical Medicine, Brigadier Julian Lewthwaite, Director of Army Community and Occupational Medicine, Mrs Margaret Sims of the Ministry of Defence Medical Statistics Branch and the numerous people who provided advice and information. Without their assistance this work would not have been possible.

\section{REFERENCES}

1. Summary Health Statistics for UK Service Personnel 19771986. Med Stats MOD Stanmore, October 1987.

2. Conover W J. Practical Non-parametric Statistics, 2nd Edition 1980, Wiley, 250-261.

3. Share of Training Costs of Service Personnel. Central Accounting Policy Notice No 6, MOD. 1984.
4. Capitation Rate Booklets, Army Personnel, Ministry of Defence 1981-1988.

5. CulLis J G and WEST P A. The Economics of Health, 1979, Oxford, 197-202.

6. A Survey of Lower Limb Injury in Recruits: Preliminary Report. APRE Report 404. 1987.

7. Wilson K C M, Evans-Smith E and Oelman B J. A Studyo of Patello-Femoral Pain in a Junior Infantry Training Unit. J R Army Med Corps 1983; 129: 82-87.

8. SinClair D M. The Enlistment Medical Examination $\underset{\overrightarrow{\mathrm{S}}}{\overrightarrow{\mathrm{S}}}$ Reasons for Failure. J R Army Med Corps 1987; 133:0 $41-42$.

9. LYNCH-Blosse R H. A Study into Medical Wastage of $\frac{\overline{\bar{D}}}{\overline{\mathrm{p}}}$ Recruits. J R Army Med Corps 1987; 133: 43-49.

10. Tointon J A. Sports Injuries in the Services 1969-1980. $\mathbb{D}$ $R$ Army Med Corps 1984; 130: 193-197.

11. Ferguson J C, MCNally M S and Booth R S. AccidentialInjuries among Naval Personnel by Occupation, Duty. Status and Pay Grade. Accid Anal \& Prev 1985; 17: 79-86.

12. LYNCH P. Alcohol Associated Deaths in British Soldiers. $J_{\mathscr{C}}$ $R$ Army Med Corps 1987; 133: 34-36.

13. Dunbar J A. Alcohol Associated Deaths in British Soldiers (letter to the Editor). J R Army Med Corps 1987; 133: 179-180.

14. Highways Economics Note no 1. Department Transport, September 1985.

15. OsMOND W G. Estimating the Full Cost of Trafte Accidents Affecting the British Army. Cranfield Institime of Technology 1983, MSc Thesis.

16. AtKINSON R W and WRIGHT D S. Impact, Drive Alive, 1988.

17. Manning and Recruiting in the Lean Years of the Ninet (the MARILYN Report). Ministry of Defence, 1988. 